\title{
Study on the Governance Innovation under Internationalization
}

\author{
Zhang $Y i$ \\ School of Finance and Public Management \\ Yunnan University of Finance and Economics \\ Kunming, P.R.China \\ Jenny_zhang186@126.com
}

\begin{abstract}
Under the new situation of global integration, public governance must conform to the trend of the times, integrate new elements, and develop innovative thinking in order to cope with new challenges. This paper first analyzes the opportunities and challenges faced by the development of public governance innovation thinking under the background of internationalization, and then puts forward corresponding development countermeasures based on the current situation.
\end{abstract}

Keywords-Internationalization, Governance, Opportunities and Challenges, Innovations

\section{INTRODUCTION}

One of the direct consequences of the development of globalization is the contradiction between the growing global problem and the relative lag of the existing political entities' ability to govern. It adds new content to public management and puts forward new challenges. Global governance reflects the new trend of international public management..

From the point of view of global public products, the internationalization of public management is an inevitable trend. With the continuous development of global economy and politics, more and more serious international common problems have put forward severe challenges to all countries and even all human beings. If they are not handled properly, it will damage the interests of many people and even the whole human beings. And because the measures taken to it often exceed the scope of sovereignty, a single country or region can not deal with it at all. This requires the countries of different regions of the world to cooperate with each other to a certain extent, to integrate resources and to improve the ability to deal with the comprehensive management of public management.

\section{THE DEFINITION AND CONNOTATION OF THE}

\section{GOVERNANCE}

On the concept of governance, in 1992, Rossi Nagan elaborated on the classic work of "governance without government". He believed that governance and rule were different conceptually, which was a kind of activities supported by common goals, which could come from the legal and formal responsibilities, or not as well. This does not rely on police force to force people to obey. Governance is a broader phenomenon than rule. Moreover, rule exists only in the realm of clear boundaries, while governance is not separable from the world order, and is not limited to a single field. In the preamble to the book "governance in the world of globalization", Robert Owen Keohane and Nai said: "governance is the collective behavior of a group that is guided and restricted by formal and informal procedures and systems." The global governance committee, in its 1995 report, defines global governance as "the sum of all kinds of individuals, groups - public or everyone's common services." This is a continuous process through which various conflicting and different interests are expected to be reconciled and cooperative action taken.

Although all kinds of explanations are different, the concept of governance does not involve three core parts: first, the object of governance is global public issues. Second, the process of governance is how to overcome the dilemma of collective action, or how to organize collective action. Third, whether the relevant subjects can and how to achieve the necessary international system of governance through negotiation.

\section{OPPORTUNITIES AND CHALLENGES FACING THE GOVERNANCE UNDER INTERNATIONALIZATION}

Under the background of current internationalization, countries in the world have close economic and social contacts, frequent personnel exchanges and frequent movements. The whole world has formed a globalized network, which inevitably brings new opportunities and challenges to public governance.

\section{A. Opportunities for the Governance}

Globalization has indeed played a major role in the development and progress of human society. However, globalization is a "double-edged sword", which has both advantages and disadvantages. It not only accelerates the development of the world economy and the popularization of science and technology, but also contains the risks and challenges, which makes the human being faced with the constraints and troubles of a large number of global public problems.

The so-called global public problem refers to the common problems that arise beyond the jurisdiction of traditional sovereign states in the process of international exchange. Global public problems are not the problems faced by individual countries, but the common problems faced by many countries and even the global community. In fact, public problems have always existed. Since the inter state relations, public problems such as war and peace, development and prosperity have always existed. Nowadays, under the tide of globalization, the scale and scope of global public problems have expanded from the security issues in the high political fields of early international relations to the social and development problems in the low political fields. Environmental pollution, climate warming, transnational 
crime, global security and so on are all phenomena in international relations after World War II. In the international community after the cold war, with the development of economic globalization, the global public problems have become increasingly prominent. Facing a series of problems such as environmental ecological problems, population expansion, the gap between the rich and the poor, terrorism, regional conflicts and nuclear weapons proliferation, a country is difficult to resolve. These problems are not just a country's problem, but a problem faced by every country. At the same time, the existence of these problems also makes the human society a community of fate. Only by strengthening cooperation among pluralistic actors and implementing global governance can the tumor be cured.

The urgency of governance in contemporary international relations is directly related to the large number of global public problems emerging in the process of globalization and interaction among countries. The rise of global public problems objectively puts forward the necessity of global governance, that is, whether the international community can and how to take action, reach agreements and implement these agreements, and complete global governance of public issues has become a special concern.

\section{B. Challenges facing the governance}

In today's world, global challenges emerge in endlessly, global governance has encountered bottlenecks, faced with problems such as governance deficit, governance failure, system supply shortage, and system need to be perfected.

\section{1) The plight of sovereign states in global governance.}

There is no doubt that the object of governance is global public problems. However, there are divergent opinions about who dominates global governance. Some people believe that international organizations play an important role in global governance and should play a leading role in global governance. Some people also value the role of non state actors such as transnational corporations and individuals in global governance. In the international community, there is no unified and worldwide government, which makes it more difficult to govern the public problems in the international community without public authority, and far more difficult to govern the public problems in the domestic society of the public authority. Because of the contradiction between the indivisibility of public goods and the exclusiveness of state sovereignty, the sovereign state appears weak in the face of these new problems. In addition, the participation of other public actors outside the sovereign state poses a challenge to the status of the sovereign state in the global governance.

\section{2) The developed countries are inadequately powered by} public products.

The allocation of international responsibility for global governance is essentially a requirement for big powers, especially developed countries, to shoulder more responsibilities. The key point of cooperation among the countries of the world is to assume international responsibility for big powers. For great powers, especially the superpowers, they have a strong ability to avoid and reduce the harm that global problems bring to their own countries, so the motivation for global cooperation is not strong. Therefore, we see that the initiative of big powers, especially superpowers, is less active than that of small and medium-sized countries.
Taking the field of global economic governance as an example, the pressure of global economic growth and development is still great, and the demand for public goods is huge. The slow recovery of the developed economies, the growing domestic problems, little interest in the provision of global public goods, and the increasing contribution of the emerging economies, have not enjoyed a symmetrical international discourse power.

\section{3) In global governance, the political goals of different} countries are not consistent.

The incompatibility of this goal affects the cooperation of global governance. For example, after 2001, the United States regards terrorism as the primary task of global governance. Developing countries will tackle poverty as a top priority, while Western European countries regard environmental protection as their top priority. Even if there is a principled consensus on a global governance issue, the goal may still be inconsistent on specific issues. For example, before 2014, Western European countries and Japan believed that the focus of environmental protection was to prevent air pollution. China believed that the focus of environmental protection was to prevent river water pollution, while the United States believed that environmental protection was the focus of preventing marine pollution. The disunity of specific targets makes it difficult for them to collaborate on the key points of environmental protection technology development.

4) There is a regular vacuum in the field of new problems.

In some emerging and non-traditional security areas, such as cyberspace and other global public governance, there are rules vacuum, lack of public goods, and governance deficit. In many areas of traditional problems, governance has been governed by law, and these emerging areas lack recognized, mature and referable laws, regulations, or rules. On the one hand, this incapable and unruly state shows the current situation of the public product deficit, and on the other hand, it is easy to create a system that is not neutral on the soil of freedom of action.

\section{SUGGESTIONS ON THE GOVERNANCE INNOVATION}

\section{UNDER INTERNATIONALIZATION}

To design an ideal governance mode and change the current situation of deficit management, we must deeply understand the new background of the times and suit the remedy to the case.

\section{A. Establishing the goal of Governance: Sustainable \\ Development}

From the perspective of global governance, sustainable development is the ultimate goal, because sustainable development is almost the best way to solve global problems. As a comprehensive concept of development, sustainable development profoundly affects and changes human economic behavior and lifestyle, and adjusts the relationship between human economic and social activities and nature. From the current situation, sustainable development is a common task of all mankind, but in fact, developing countries 
are facing more difficult problems. On the one hand, developing countries should pay attention to dealing with the relationship between the present and the future. On the premise of meeting the basic living requirements of the present people, the developing countries should restrict the speed of economic growth properly; on the other hand, we should actively use advanced technology to reduce the damage to the environment by economic growth.

Whether it is the United Nations "sustainable development goal (SDG)" or the "humanitarian agenda" proposed by the world humanitarian summit, all countries of the world have formed a global consensus on the realization of the sustainable development of political, economic, cultural and social aspects. In this context, how to promote the organic integration of humanitarian and sustainable development has become the focus of attention of all countries. However, it is not easy to realize the combination of humanitarianism and development globally. Combining humanitarian action with national development strategy, strengthening infrastructure construction, solving the problem of poverty in development and improving the ability to rescue disaster self rescue are the key keys to the organic combination of humanitarianism and development.

\section{B. Adhere to the basic principles of win-win cooperation}

As economic activities are organized around the world, transnational exchanges and exchanges are increasingly frequent, regional and cross regional affairs have increased rapidly, and global public problems are becoming more and more widespread. In the era of globalization, all countries have formed an interdependent destiny community because of global problems. Each country is affected by the behavior of other countries. The result of participation depends partly on the choice made by other participants, and the income is partly dependent on the behavior of other members. The narrow and individual rational mode of solving the problems on the basis of national geographic boundaries leads to the potential deterioration of global problems, and the global public interests are often not able to be maintained. This shows that international public management must introduce new development and follow the basic principles of win-win cooperation to meet the requirements of the era of globalization. On the one hand, the international community has the common interest needs to participate in governance, and our global governance system is based on such interests. On the other hand, in the process of realizing international cooperation, the political and economic conditions added to the aid parties and the transfer and loss of the interests of the countries of the aid countries will be involved. At this time, the two sides should engage in dialogue on the basis of seeking common ground and reserving differences, and realize mutual benefit and mutual benefit on the basis of common interests.

\section{Opening up multiple financing channels}

Create diversified financing channels and maintain effective supply of public goods. The government, as the representative of public interest, is the leader of the supply of public services, which is determined by the nature of public services and the stipulations of government functions. Market and social organizations are important participants in the supply of public services. Their participation will help to integrate social resources, stimulate social vitality, and effectively meet the needs of individualized, diversified and hierarchical public services. The synergy between multiple subjects is a procedural guarantee for the effective supply of public services. The key to the integration of various social resources, the key to the formation of the normalization and the rule of law, the relationship between the division of labor and the power and responsibility, and the effective division of labor and responsibility in power and responsibility. First of all, there should be a clear division of responsibilities and powers on the legal system; secondly, we should have a detailed and clear cooperation goal and work hard for this purpose. Again, we should have a sound coordination mechanism to coordinate each other's behavior through information sharing, joint solutions and other consultative ways to form a complementary advantage. In the end, we should establish the corresponding mechanism of responsibility sharing and accountability in order to ensure that the main body of supply always fulfil the responsibility of public service.

\section{Establish a comprehensive and systematic feedback mechanism for supervision and evaluation.}

Scientific and standardized feedback mechanism of supervision and evaluation is an important guarantee for the internationalization of public governance. Whether governance is compatible with the global economic and social development level, the effect of governance, whether it meets the needs of the international public, and whether it helps to promote the international public interests, needs supervision, evaluation and feedback.

Judging from the standards of supervision and evaluation, it is the key to define the contents of supervision and assessment. Generally speaking, the contents of supervision and assessment can be seen from two aspects: On the one hand, it is evaluated from the point of view of the subjective and objective. Whether objective standards meet the requirements of international public service related documents such as international laws, regulations, regulations, policies, management systems, reports, standards and other international public service documents; and whether the subjective standards meet the expectations and requirements of the international public and other relevant stakeholders. On the other hand, it is evaluated from the perspective of process results. The evaluation of the results mainly focuses on what services provided by the government and the results of the service; the process assessment focuses on how the government and other public departments and social organizations provide services, and the process of the whole service is standardized. Of course, all kinds of evaluation subjects and evaluation methods have advantages and disadvantages. In practice, on the basis of understanding the concerns of various assessment subjects, it is necessary to scientifically plan their respective evaluation contents and to arrange their assessment scope reasonably, establish a systematic evaluation index system, select appropriate evaluation methods, and feedback the evaluation results in time, According to the evaluation results, the adjustment and reaction will be made in time to create a full range of multi angle and stereoscopic and institutionalized international public service supervision and evaluation feedback chain, so as to provide important guarantee for promoting the modernization of international public service. 


\section{THE CONCLUSION}

In a word, both government organizations and intergovernmental organizations can not solve global public problems effectively by virtue of existing forces. The rapid growth of public service demand in the international community is in sharp contrast to the level of existing public service. "The state is not only too small to solve big problems, but also becomes too big to solve small problems." All this makes it clear to us that the advent of the era of globalization has put forward new demands on international public administration. In the context of internationalization, it is necessary to accelerate the pace of innovation for public governance.

\section{ACKNOWLEDGMENT}

The writing of this paper would like to thank the family and Mr Zhang's support.

\section{REFERENCES:}

[1] Hou Jing. Opportunities and challenges for the development of public management innovative thinking. [J]. era finance, 2017,30 (8) (In Chinese)

[2] Liu Zhichang. National governance and modernization of public service. Hangzhou: Zhejiang people's publishing house,.2015(In Chinese).

[3] $\mathrm{Hu}$ Zhiping. The public service path of national governance modernization. Explore.2015 (6). (In Chinese)

[4] Chen Chao Jun. The quality of public service: a concept that needs to be redefined and interpreted. Journal of the Party School of Tianjin Municipal Committee of the CPC.2017 (2). (In Chinese)

[5] Li Hongjia and Shen Yaping. Theoretical paradigm and practical path of public service supply side reform. Journal of Tianjin municipal Party school.2017 (2) (In Chinese) 